\title{
Análise de Sustentabilidade Ambiental em uma indústria de bebidas: um enfoque no processo produtivo
}

Environmental Sustainability Analysis in a beverage industry: focus on the production process.

\author{
Fernando Richartz \\ Graduando em Ciências Contábeis pela Universidade Federal de Santa Catarina \\ Endereço: Rua Senador Alberto Paqualine, 34 \\ CEP: 88090-400 - Florianópolis/ SC \\ E-mail: nandorichartz@hotmail.com \\ Telefone: (48) 8406-6422
}

\section{Cláudio Luiz de Freitas}

Graduando em Ciências Contábeis pela Universidade Federal de Santa Catarina

Endereço: Rua Douglas Seabra Levier, 61 - Apto. 303-A

CEP: 88.040-410 - Florianópolis/ SC

E-mail: freitasclf@hotmail.com

Telefone: (48) 9168-9947

\section{Elisete Dahmer Pfitscher}

Doutora em Engenharia de Produção pela Universidade Federal de Santa Catarina

Professora do Mestrado em Ciências Contábeis da Universidade Federal de Santa Catarina

Endereço: Rua Mário Cândido da Silva, 46 - Bairro Itaguaçu

CEP: 88.085-475 - Florianópolis/ SC

E-mail: elisete@cse.ufsc.br

Telefone: (48) 8817-2019 ou (48) 3364-2028

Artigo recebido em agosto de 2009. Passou por uma avaliação double blind review em novembro de 2009. Aceito em dezembro de 2009 pela Editora Científica Sandra Rolim Ensslin. Artigo apresentado no XVI Congresso Brasileiro de Custos, 2009, Fortaleza, 2009 


\title{
Resumo
}

Um dos principais causadores de impactos ambientais nas indústrias é seu processo produtivo, responsável pela produção de resíduos que podem causar grandes danos ao meio ambiente. O objetivo deste trabalho é analisar a sustentabilidade ambiental de uma indústria de bebidas, com enfoque em seu processo produtivo. Para isso, realizou-se um estudo de caso, de caráter exploratório, com abordagem quali-quantitativa. $\mathrm{O}$ estudo foi dividido em três fases, sendo a primeira a Fundamentação Teórica; a segunda fase, a Análise de Sustentabilidade; e a terceira e última fase, a aplicação do Plano Resumido de Gestão Ambiental 5W2H. Os resultados apontam que a empresa apresenta uma boa sustentabilidade ambiental, mas possui aspectos a serem melhorados. No que se refere ao processo produtivo, o resultado da sustentabilidade ambiental foi considerado bom, mas a empresa apresentou aspecto deficitário que comprometeu seus resultados e, portanto, podem ser melhorados e, consequentemente, melhorar a sustentabilidade global dessa indústria de bebidas.

Palavras-chave: Análise de Sustentabilidade Ambiental, Gestão Ambiental-5W2H, Indústria de Bebidas.

\begin{abstract}
One of the major sources of environmental impact at industries is its production process, which is responsible for the creation of residues that can damage the environment severely. This paper analyzes environmental sustainability in a beverages industry by focusing on its production process. To achieve this goal, an exploratory case study was conducted, employing a quantitative-qualitative approach. The study was divided into three parts, beginning with the Theoretical Background, followed by the Sustainability Analysis, and the application of the summarized environmental management Plan 5W2H. The results indicate that the firm presents a good level of environmental sustainability, but there is still room for improvement. Regarding the production process, good results were obtained for environmental sustainability, but the company presented faulty aspects which hindered its results and can be enhanced in order to improve the global sustainability of this beverages industry.
\end{abstract}

Key words: Environmental Sustainability Analysis. Environmental Management - 5W2H. Beverages Industry.

\section{Introdução}

O processo produtivo, originário das indústrias e obviamente fundamental a estas e indiretamente a toda a sociedade à qual a indústria está inserida, está cada vez mais sofisticado.

Vítimas da globalização e de um mundo cada vez mais dinâmico, no qual cada instante representa uma nova invenção, uma nova criação, as indústrias se veem obrigadas a se render às tecnologias mais modernas, pois apresentam melhores condições de competitividade em um mercado exigente e seletivo.

É esse mesmo mercado que exige das indústrias compromisso com a sociedade a qual está inserida, compromisso este representado pelas condições que a empresa apresenta a seus colaboradores e à comunidade em geral e, principalmente, compromisso com o meio ambiente, representando assim uma preocupação com a qualidade de vida.

Nesse sentido, as empresas muito têm se preocupado com os impactos 
provocados por seus processos produtivos ao meio ambiente e em como promover uma gestão ambiental eficiente, causando, dessa forma, menores danos ao meio ambiente e reforçando suas políticas de responsabilidade sócio-ambiental.

Este estudo fica resumido a duas questões-problema: (i) Qual a sustentabilidade ambiental global da indústria? (ii) Qual a sustentabilidade ambiental evidenciada no processo produtivo?

Nesse contexto, o presente trabalho propõe analisar o comportamento da sustentabilidade ambiental de uma indústria de bebidas, evidenciando seu processo produtivo, a fim de se verificarem os impactos causados por esse processo por meio das ferramentas de gestão ambiental com suporte da Contabilidade, caracterizando-se, assim, como objetivo geral deste estudo.

Justifica-se a escolha de uma indústria de bebidas, por ser uma das indústrias mais evidentes, e por ainda não existirem muitos trabalhos abordando esse ramo de atividade econômica. Além disso, essa indústria é responsável pelo abastecimento da marca da qual é franqueada em todo o estado de Santa Catarina.

Este artigo está organizado da seguinte maneira: esta primeira seção de caráter introdutório; na segunda seção, apresenta-se a fundamentação teórica que dá suporte às discussões apresentadas no trabalho. A seção 3 aborda a metodologia e a trajetória metodológica, seguida da seção 4, na qual se discute o estudo de caso realizado neste trabalho e seus resultados. Na seção 5, têm-se as considerações finais e sugestões para futuros trabalhos e, por fim, apresentam- se as referências bibliográficas.

\section{Metodologia da Pesquisa}

Esta seção aborda os procedimentos para condução do trabalho, apresentando o seu enquadramento metodológico, seguido dos procedimentos de revisão de literatura e da trajetória metodológica, que apresenta rapidamente os principais aspectos deste estudo.

Com relação ao enquadramento metodológico, este estudo é de natureza exploratória, que, de acordo com Gil (2002, p. 41),

tem como objetivo proporcionar maior finalidade com o problema com vistas a torná-lo mais explicito ou a construir hipóteses. Pode-se dizer que estas pesquisas têm o objetivo principal o aprimoramento de idéias ou a descoberta de intuições.

É caracterizado como um estudo de caso que, para Yin (2005, p. 19),representa acontecimentos e quando o foco se encontra em fenômenos menos 
contemporâneos inseridos em algum contexto da vida real.

A coleta dos dados que fundamentam as análises apresentadas aqui são de fonte primária, pois são dados coletados diretamente em campo, por ser um estudo de caso. Esses dados foram coletados na empresa.

Este trabalho possui abordagem quali-quantitativa, uma vez que apresenta envolvimento de dados estatísticos que remetem à abordagem quantitativa, mas também é utilizada a abordagem qualitativa em alguns momentos.

Segundo Richardson (1999), "os estudos que empregam uma metodologia qualitativa podem descrever a complexidade de determinado problema, analisar a interação de certas variáveis, compreender e classificar processos dinâmicos vividos por grupos sociais".

Já a abordagem quantitativa geralmente implica a utilização de questionários e o envolvimento estatístico para a análise dos dados.

Para a realização deste trabalho, fez-se uma verificação in loco, realizada por um dos autores, onde se aplicou uma lista de verificação composta de 123 questões. Além disso, considerou-se necessária a realização de uma entrevista com dois funcionários da empresa, sendo um técnico e o outro, graduado em Química.

Para a revisão de literatura, adotaram-se teses e artigos científicos como fontes de informação. Para a utilização de artigos científicos como revisão de literatura, delimitou-se a busca aos artigos publicados nas duas edições do Congresso UFSC de Controladoria e Finanças \& Iniciação Científica em Contabilidade. Procedeu-se a busca pelos títulos que remetiam ao tema Contabilidade Ambiental, sendo selecionados 12 artigos. Em seguida, buscou-se nestes os que continham pelo menos uma das seguintes palavras-chave: Gestão Ambiental, Contabilidade Ambiental, GAIA, SICOGEA e 5W2H. Selecionaram-se, então, oito artigos e partiu-se então para a leitura dos seus resumos, a fim de se chegar aos seis artigos que compuseram a fundamentação teórica deste estudo juntamente com as teses.

A trajetória metodológica deste estudo dividiu-se em três fases: a revisão teórica, que resgata os principais conceitos trabalhados neste artigo; o estudo da gestão ambiental em uma indústria de bebidas; e a evidenciação da gestão ambiental no processo produtivo dessa indústria, ambas com a aplicação do $5 \mathrm{~W} 2 \mathrm{H}$, evidenciados pelo SICOGEA e GAIA.

\section{Fundamentação teórica}

Resgatam-se, nesta seção, os principais conceitos abordados neste artigo. Para tanto, foram definidos como mais relevantes os seguintes assuntos: Contabi- 
lidade Ambiental, Gestão Ambiental, GAIA, SICOGEA e Indústria de Bebidas.

\subsection{Contabilidade Ambiental}

A Contabilidade como ciência social aplicada não é apenas uma ferramenta de suporte à Administração de Empresas, mas é principalmente um instrumento de elaboração, divulgação e informação dos fatos ocorridos em uma entidade, para que se tornem elucidativos aos stakeholders.

Assim, quando se fala dos stakeholders, tem-se uma visão ampla dos inúmeros usuários da Contabilidade e da informação gerada por ela. Informações essas que não se limitam ao desempenho econômico e financeiro da empresa, mas saem dos limites da empresa e afetam a sociedade e o meio ambiente em que ela está inserida.

A Responsabilidade Social expressada pelas ações dos gestores das empresas que estão inseridas nesse contexto, na visão da teoria dos stakeholders, mostram que as empresas possuem responsabilidades para com os envolvidos, denominados agentes, entre os quais as comunidades que podem beneficiar-se dessas ações. As empresas, nesse sentido, podem obter novas oportunidades, tais como ganhos de reputação (MACHADO FILHO, 2006).

Para Tinoco e Robles (2006), a Contabilidade assume o controle dos recursos mínimos fornecidos e do amplo uso de materiais reciclados e renovados. Assume também o controle dos processos produtivos e investimentos em imobilizado, preocupando-se, então, com o uso racional de água e energia e com os resíduos gerados pelo processo produtivo.

De acordo com Araújo et al. (2007), é nesse sentido que surge a Contabilidade Ambiental. Campanhol, Smith e Paula (2007) complementam afirmando que a Contabilidade é um método adequado para a divulgação das informações referentes ao meio ambiente, pois serve de intermediária e, portanto, facilitadora das ações da gestão ambiental e dos usuários das informações: os stakeholders.

Dessa forma, a Contabilidade Ambiental pode ser entendida como uma ramificação da Contabilidade, capaz de evidenciar aspectos externos à entidade, mas diretamente ligados às suas ações.

Nesse sentido, Kraemer (2006) afirma que a Contabilidade, com base nos indicadores e dados fornecidos, permite análise e avaliação das informações relacionadas à atuação ambiental da entidade, permitindo melhora periódica dos procedimentos. Kraemer (2006) também enfatiza que a Contabilidade está inserida em um contexto que facilita o processo decisório com relação à atuação ambiental da empresa.

A Contabilidade de Gestão Ambiental está em conformidade com a Divisão para o Desenvolvimento Sustentável. Quando se fala em Contabilidade Ambiental, 
faz-se necessário também falar em gestão ambiental, tratando-se desse assunto na sequência.

\subsection{Gestão ambiental}

A gestão sócio-ambiental deve visar ao equilíbrio entre os elementos, a política e a relação com o meio ambiente, entendendo-se esses itens, respectivamente, como os aspectos, as decisões e os impactos ambientais (FERREIRA et al., 2008).

Freitas et al. (2008) afirmam que a gestão ambiental é o processo de busca pela qualidade ambiental causada pela empresa à sociedade.

Kraemer (2002) define gestão ambiental, como

o sistema que inclui a estrutura organizacional, atividades de planejamento, responsabilidades, práticas, procedimentos, processos e recursos para desenvolver, implementar, atingir, analisar criticamente e manter a política ambiental. É a forma pela qual a organização se mobiliza, interna e externamente para a conquista da qualidade ambiental desejada.

Gerenciar os impactos ambientais causados por uma entidade é algo que exige conhecimento acerca da empresa e do meio ambiente. A gestão ambiental é o processo que dá suporte às ações desenvolvidas pela empresa a fim de minimizar impactos ambientais e é evidenciada pela Contabilidade Ambiental.

\section{$3.3 G A I A$}

O GAIA é um método de Gerenciamento de Aspectos Ambientais, resultado da tese de doutorado do professor Alexandre de Ávila Lerípio, em 2001.

O GAIA é um conjunto de instrumentos e ferramentas gerenciais com foco no desempenho ambiental aplicável aos processos produtivos de uma dada organização, o qual procura integrar, através de etapas seqüenciais padronizadas, abordagens relativas à sensibilização das pessoas e à melhoria dos processos, utilizando para tal princípios de seus fundamentos teórico-conceituais (LERÍPIO, 2000, p. 66).

De acordo com Araújo et al. (2007), o GAIA é uma ferramenta que busca motivar as pessoas para a melhoria do desempenho ambiental, com todos os pressupostos básicos reconhecidos pela NBR ISO 14.001.

Nesse contexto, Lerípio afirma que é objetivo do método GAIA

Proporcionar às organizações o atendimento à legislação, a melhoria contínua e a prevenção da poluição a partir de atividades focalizadas no desempenho ambiental e na sustentabilidade tomando como elementos fundamentais do processo à organização e as pessoas 
através de suas relações com o meio ambiente.

Na mesma linha, evidenciando a gestão ambiental, tem-se o SICOGEA, que é apresentado na seção 3.4.

\subsection{SICOGEA}

O SICOGEA é um Sistema Contábil Gerencial Ambiental, desenvolvido pela professora Elisete Dahmer Pfitscher, em 2004, em sua tese de doutorado. Segundo Muller et al. (apud PFITSCHER, 2004), o SICOGEA

[...] contempla um ambiente corporativo de parcerias, com interesses comuns. Trata-se de um processo complexo, onde os gestores devem trabalhar numa linha de conscientização na preservação do meio ambiente com redução de impactos nocivos e probabilidade de sustentabilidade das empresas envolvidas.

Linauer (2003, apud PFITSCHER, 2004) complementa a posição de Muller et al. (apud PFITSCHER, 2004), dizendo que "é um sistema capaz de mostrar a problemática aos centros de pesquisa e estudo e possibilitar tecnologias simples e eficientes no sentido da preservação ambiental e da sustentabilidade das empresas envolvidas".

Para Baldissera et al. (2008), após a aplicação do SICOGEA, os gestores podem planejar e desenvolver métodos que tornem o processo produtivo mais eficaz em relação à gestão ambiental.

\subsection{Indústria de Bebidas}

As empresas que investem em meio ambiente podem ter melhorias em seu desempenho econômico, financeiro, ambiental e social, proporcionando aumento de produtividade dos recursos utilizados nos processos produtivos e, nessa perspectiva, poupar recursos, assim, pode ser considerada receita, além da contribuição de evitar ou reduzir os impactos ambientais (TINOCO \& KRAEMER, 2004).

De acordo com Freitas et al. (2008), "por fabricante de bebidas entendese o estabelecimento industrial que em um processo produtivo une as matériasprimas, e a partir daí dando origem à bebida".

$\mathrm{O}$ site Wikipédia reforça a afirmação do autor, apresentando como o conjunto de atividades que prepara ingredientes que compõem a bebida para comercialização.

\section{Estudo de caso}


Nesta seção, apresenta-se a empresa objeto das análises deste estudo juntamente com a sustentabilidade ambiental global e faz-se uma breve discussão acerca dela. Na sequência, aborda-se a sustentabilidade ambiental do processo produtivo.

\subsection{A empresa e as ações sócio-ambientais desenvolvidas}

A Vonpar Refrescos S.A., empresa objeto das análises deste estudo, é uma indústria de bebidas, instalada na região da grande Florianópolis, estado de Santa Catarina. A empresa é franqueada da Coca-Cola, produzindo e distribuindo seus produtos, além de distribuir os produtos da Femsa Cerveja Brasil e Água Mineral Charrua (www.vonpar.com.br).

A empresa atende aproximadamente a $73,5 \%$ do estado do Rio Grande do Sul, por meio de fábricas e centros de distribuições instalados nesse estado, e $100 \%$ do estado de Santa Catarina.

A indústria produz em média 70 milhões de litros de bebidas por mês e respondeu por um faturamento bruto na ordem de R\$ 1.185 bilhões em 2007.

No que tange à responsabilidade social, a empresa desenvolve várias ações em suas várias unidades de produção e distribuição, como o projeto Prato Popular, que serve refeições ao valor de $\mathrm{R} \$ 1,00$ à comunidade mais necessitada, em Porto Alegre; o projeto Alimentação Solidária, que colabora com a alimentação diária de cerca de 60 crianças em uma creche de Porto Alegre; e o projeto Pescar, que prepara jovens em situação de vulnerabilidade para entrarem no mercado de trabalho. Além disso, a Vonpar apoia o projeto Parceiros Voluntários.

Em Santa Catarina, a empresa apoia o PROERD - Programa Educacional de Resistência às Drogas e à Violência; patrocina a Feira da Esperança, que angaria fundos para a Apae e a Escolinha de Futebol Craque Mirim, em Antonio Carlos, município onde se localiza sua fábrica no Estado, além de participar das ações promovidas pelo Instituto Coca-Cola Brasil.

A Vonpar Refrescos S.A. realiza várias ações de apoio à cultura e seu desenvolvimento, dentre elas destaca-se a parceria com a Escola do Teatro Bolshoi no Brasil e o patrocínio à Orquestra de Câmara do Theatro São Pedro, em Porto Alegre.

E o compromisso da empresa com a sociedade não se resume em ações de patrocínio e apoio, pois se notou o seu compromisso com os colaboradores, quando da visita realizada pelos autores, pois a empresa exige que seus funcionários mantenham o uso constante de equipamentos de segurança e, mesmo não havendo acidentes, possui uma EGI - Equipe de Gerenciamento de Incidentes, sempre alerta na empresa, caso alguma anormalidade ocorra em suas operações. 
A empresa ainda coloca lixeiras para coleta seletiva e coletores de materiais radioativos, como pilhas e baterias, à disposição de seus colaboradores.

No que se refere à responsabilidade ambiental, a empresa também não se omite e desenvolve várias ações, como o Projeto Gente Cuida de Gente, que capacita coletores de lixo reciclável; e o uso de biodiesel em sua frota de caminhões.

Na fábrica, no município de Antônio Carlos, observou-se que a empresa mantém uma grande vegetação nos seus arredores, onde habitam inúmeras aves, mostrando uma realidade pouco comum em indústrias localizadas em regiões metropolitanas.

Com relação ao seu processo produtivo, a Vonpar ainda demonstra grande preocupação com os impactos que produz ao meio ambiente, uma vez que menos de $1 \%$ do que produz de resíduos sólidos é reciclado, proporcionando, ainda, retorno financeiro que se caracteriza como receita ambiental.

Notou-se também que a empresa se preocupa em não prejudicar o meio ambiente, seja pela poluição causada por seu processo de produção, seja pela utilização de recursos não renováveis. Nesse sentindo, a Vonpar vem trabalhando na implantação de sistemas que minimizem os danos provocados ao meio ambiente. Só em 2008, a empresa investiu mais de quatro milhões de reais na instalação de um sistema que transforma os resíduos líquidos gerados pelo processo produtivo em biogás. A tecnologia é importada das melhores indústrias européias e, no Brasil, só existe em duas unidades da Vonpar, sendo uma dessas unidades, a de Antonio Carlos, em Santa Catarina.

Com o sistema citado acima, a empresa consegue separar a água das demais substâncias contidas nos resíduos, garantindo que a água proveniente do processo produtivo saia com $99 \%$ de pureza, quando a legislação prevê que a água saia com $80 \%$ de pureza, no mínimo. O biogás resultante desse processo é utilizado para alimentar as caldeiras, promovendo grande economia nas atividades da empresa.

\subsection{Análise de sustentabilidade ambiental global}

Para a realização desta análise, utilizou-se de verificação in loco em uma unidade fabril da empresa, com aplicação de uma lista de verificação e entrevista com dois funcionários, sendo um técnico e um graduado em Química, responsáveis pelos processos produtivos da unidade.

$\mathrm{Na}$ realização das análises apresentadas aqui, foram utilizados o SICOGEA - Sistema Contábil Gerencial Ambiental, advindo da tese de doutorado da professora Elisete Dahmer Pfitscher, e do GAIA - Gerenciamento dos Aspectos e Impactos Ambientais. 
Para o cálculo da análise de sustentabilidade ambiental, utilizou-se a fórmula apresentada a seguir, proveniente da tese de doutorado do professor Alexandre de Ávila Lerípio.

\section{Total de quadros adequados $\times 100=$ Índice de Sustentabilidade Total de quadros - Não se Adapta}

Após o cálculo, realiza-se a avaliação da sustentabilidade da empresa, com base no Quadro 1, adaptada de Lerípio (2001) e Miranda e Silva (2002).

Quadro 1: Avaliação da sustentabilidade e desempenho ambiental

\begin{tabular}{|c|c|l|}
\hline RESULTADO & SUSTENTABILIDADE & $\begin{array}{c}\text { DESEMPENHO: CONTROLE, INCENTIVO, } \\
\text { ESTRATÉGIA COMPETITIVA. }\end{array}$ \\
\hline Inferior a $50 \%$ & Deficitário & Fraco: Pode estar causando danos ao meio ambiente. \\
\hline Entre $51 \%$ a $70 \%$ & Regular & Médio: Atende somente a legislação. \\
\hline Mais de $71 \%$ & Adequado & $\begin{array}{l}\text { Alto: Valorização ambiental com produção ecológica } \\
\text { e prevenção da poluição. }\end{array}$ \\
\hline
\end{tabular}

Fonte: Adaptado de Lerípio (2001) e Miranda e Silva (2002).

Com base nesse quadro, classifica-se a sustentabilidade em deficitária, regular ou adequada.

A lista de verificação aplicada foi composta de 123 questões divididas em seis critérios: Fornecedores, Processo Produtivo e Prestação de Serviços, Indicadores Contábeis, Indicadores Gerenciais, Utilização do Produto e Serviço Pós-Venda.

No âmbito global, a empresa teve sua sustentabilidade ambiental considerada adequada, com desempenho de 83,76\%.

Com relação ao critério Fornecedores, a empresa atingiu um resultado de $84,61 \%$, portanto a sustentabilidade ambiental foi adequada, assim como no critério Indicadores Contábeis, que apresentou sustentabilidade de 96\%, com um subcritério deficitário, relacionado aos Indicadores de Demonstração Ambiental Específica, mas que a empresa tem buscado soluções de melhoria nesse sentido.

No critério Indicadores de Gerenciais, o desempenho também foi satisfatório com sustentabilidade $100 \%$. O critério Serviço Pós-Venda obteve uma sustentabilidade ambiental da ordem de $77,78 \%$, portanto adequada, sendo que os únicos itens deficitários se referem à embalagem do produto que não apresenta fácil biodegradação e decomposição e por necessitar de cuidados especiais para a proteção do meio ambiente. Já o critério Utilização do Produto, o desempenho foi regular, com nível de sustentabilidade de $66,67 \%$. 
O critério Processo Produtivo e Prestação de Serviço é tratado na próxima seção com mais detalhes.

Com base nos resultados da sustentabilidade ambiental, elaborou-se o Quadro 2, que evidencia os principais pontos falhos na gestão ambiental da empresa.

Quadro 2: Prioridades de critérios, sem considerar o critério 2 Processo Produtivo e Prestação de Serviços

\begin{tabular}{|c|c|c|c|}
\hline & CRITÉRIO & SUSTENTABILIDADE & PRIORIDADE \\
\hline & $\begin{array}{l}\text { CRITÉRIO 5 = UTILIZAÇÃO DO } \\
\text { PRODUTO }\end{array}$ & $66,67 \%$ Regular & $\begin{array}{l}\text { Elaborar produtos com } \\
\text { maior durabilidade }\end{array}$ \\
\hline $2^{\circ}$ & CRITÉRIO 6= SERVIÇO PÓS-VENDA & 77,78\% Adequado & $\begin{array}{l}\text { Desenvolver embalagens } \\
\text { de fácil decomposição }\end{array}$ \\
\hline & CRITÉRIO 1 =FORNECEDORES & $84,61 \%$ Adequado & $\begin{array}{l}\text { Tentar comprar uma } \\
\text { quantidade maior de } \\
\text { produtos reciclados }\end{array}$ \\
\hline & $\begin{array}{l}\text { CRITÉRIO 3 C = INDICADORES DE } \\
\text { DEMONSTRAÇÃO AMBIENTAL } \\
\text { ESPECÍFICA }\end{array}$ & 90,9\% Adequado & $\begin{array}{l}\text { Procurar minimizar ao } \\
\text { máximo todos os resíduos } \\
\text { que causam impactos ao } \\
\text { meio ambiente }\end{array}$ \\
\hline & $\begin{array}{l}\text { CRITÉRIO 3 A = INDICADORES } \\
\text { AMBIENTAIS DE BENS E DIEITOS E } \\
\text { OBRIGAÇÕES }\end{array}$ & $100 \%$ Adequado & Sem prioridades \\
\hline & $\begin{array}{l}\text { CRITÉRIO 3 B = INDICADORES } \\
\text { AMBIENTAIS DE CONTAS DE } \\
\text { RESULTADO }\end{array}$ & $100 \%$ Adequado & Sem prioridades \\
\hline & $\begin{array}{l}\text { CRITÉRIO 4 = INDICADORES } \\
\text { GERENCIAIS }\end{array}$ & $100 \%$ Adequado & Sem prioridades \\
\hline
\end{tabular}

Fonte: Elaborada pelos autores.

O Quadro 2 evidencia as prioridades na gestão ambiental da empresa, colocando os critérios com os piores resultados primeiro. É importante ressaltar que para efeitos deste estudo não se considerou no quadro acima o critério Processo Produtivo e Prestação de Serviço, pois este é tratado na sequência com mais detalhes. Caso fosse considerado, esse critério alteraria o quadro, e o subcritério Nível de Tecnologia Utilizada figuraria como a primeira prioridade do quadro, como será mostrada na próxima seção.

Com base nas prioridades apresentada pelo Quadro 2, elaborou-se um plano resumido de gestão ambiental a fim de apresentar possíveis soluções à empresa. O plano adotado é o 5W2H (What? Why? When? Where? Who? How? How Much?), aplicado, neste caso, apenas ao critério considerado regular, que se apresenta da seguinte maneira:

UTILIZAÇÃO DO PRODUTO (critério 5)

- (What?) O quê? 
R: A empresa deveria desenvolver produtos que tivessem um maior prazo de duração, ou seja, com uma maior validade.

- (Why?) Por quê?

R: Assim ela conseguiria uma melhor satisfação entre seus consumidores e não teria tantas perdas no estoque.

- (When?) Quando?

R: O prazo estipulado para aplicar esta ideia foi de aproximadamente dois anos.

\section{- (Where?) Onde?}

R: Em toda a linha de produção da Vonpar Refrescos S.A.

-(Who?) Quem?

R: A iniciativa deve ser dos diretores, mas deve ser executada em parceria com os responsáveis pela produção da empresa

- (How?) Como?

R: Adicionando ou substituindo ingredientes que façam com que a durabilidade do produto aumente sem modificar o sabor e que também esta substância não agrida o meio ambiente

\section{- (How Much?) Quanto custa?}

R: Valores não orçados

Acredita-se que adotando esse plano resumido de gestão ambiental, a empresa possua condições de melhorar a sustentabilidade ambiental nesse critério e, por consequência, melhorar sua sustentabilidade ambiental global.

\subsection{Análise de Sustentabilidade no Processo Produtivo e Prestação de Serviço}

Este é o segundo critério constante da lista de verificação e é tratado de forma particular neste estudo, pois foi o critério que, apesar de no contexto ser considerado adequado, apresentou o subcritério de menor resultado e, portanto, o mais deficitário da gestão ambiental da empresa. Esse critério foi dividido em cinco subcritérios, como apresentado abaixo:

- Subcritério 2a - Eco-eficiência do Processo Produtivo e do Serviço Prestado.

- Subcritério 2b - Nível de Tecnologia Utilizada

- Subcritério 2c - Aspectos e Impactos Ambientais do Processo

- Subcritério 2d - Recursos Humanos na Organização

- Subcritério 2e - Disponibilidade de Capital

Esse critério apresentou nível adequado de sustentabilidade, com um resultado de 76,47\%, mas dos cinco subcritérios o Nível de Tecnologia Utilizada foi 
Deficitario, com 28,57\%. O subcriterio Eco-eficiência do Processo Produtivo e do Serviço Prestado apresentou sustentabilidade de 78,57\%, seguido do subcritério Aspectos e Impactos Ambientais do Processo, com 80\% e dos subcritérios Recursos Humanos na Organização e Disponibilidade de Capital, com 100\% cada.

O subcritério Nível de Tecnologia Utilizada era composto por sete questões, das quais duas foram consideradas adequadas e as demais deficitárias.

Tais aspectos deficitários estão relacionados com o grau de complexidade elevado do nível de tecnologia utilizada, alto nível de automação, utilização de recursos não renováveis, utilização de matérias-primas perigosas e dependência em relação a algum fornecedor e/ou parceiro.

Quanto à utilização de matérias-primas perigosas e dependência com fornecedores e/ ou parceiros é um aspecto que dificilmente a empresa conseguirá solucionar, uma vez que, por ser franqueada da Coca-Cola, a dependência se justifica, e, por consequência, a utilização de matérias-primas também se justifica, pois é do conhecimento de todos que a Coca-Cola possui ingredientes únicos que não podem ser substituídos.

Com relação à utilização de recursos não renováveis, a empresa está trabalhando para melhorar a situação com a implantação de um sistema que transforma os resíduos líquidos em biogás que será utilizado na alimentação de suas caldeiras, evitando com isso o uso excessivo de energia elétrica.

No que tange ao alto nível de complexidade da tecnologia usada e do alto nível de automação, é uma situação que também coloca a empresa em certa dificuldade para solucionar, já que é inevitável que a empresa se mantenha em condições de concorrência em um mercado cada vez mais competitivo, sem se render ao uso das mais modernas tecnologias.

Utilizando-se, então, dos resultados da análise de sustentabilidade, elaborou-se um quadro de prioridades, a fim de apresentar possíveis soluções na melhoria da gestão ambiental da empresa.

Quadro 3: Prioridade do critério Processo Produtivo e Prestação de Serviços 


\begin{tabular}{|c|c|c|c|}
\hline & CRITÉRIO & SUSTENTABILIDADE & PRIORIDADE \\
\hline $1^{\circ}$ & $\begin{array}{l}\text { CRITÉRIO 2b = NÍVEL DE } \\
\text { TECNOLOGIA UTILIZADA }\end{array}$ & 28,57\% Deficitário & $\begin{array}{l}\text { Utilizar recursos naturais } \\
\text { renováveis no processo } \\
\text { produtivo }\end{array}$ \\
\hline $2^{\circ}$ & $\begin{array}{l}\text { CRITÉRIO } 2 \text { A = ECO- } \\
\text { EFICIÊNCIA DO PROCESSO } \\
\text { PRODUTIVO E DO SERVIÇO } \\
\text { PRESTADO }\end{array}$ & $78,57 \%$ Adequado & \begin{tabular}{|lrr} 
Fazer com o & \multicolumn{1}{c}{ que o } \\
processo & produtivo \\
consuma menos & energia e \\
não produza & tantos \\
resíduos sólidos e líquidos
\end{tabular} \\
\hline $3^{\circ}$ & $\begin{array}{l}\text { CRITÉRIO } 2 \mathbf{C}=\text { ASPECTOS E } \\
\text { IMPACTOS AMBIENTAIS DO } \\
\text { PROCESSO }\end{array}$ & $80 \%$ Adequado & $\begin{array}{l}\text { Diminuir o consumo de } \\
\text { água tanto no processo } \\
\text { produtivo como em toda a } \\
\text { organização }\end{array}$ \\
\hline $4^{\circ}$ & $\begin{array}{l}\text { CRITÉRIO } 2 \text { D = RECURSOS } \\
\text { HUMANOS NA } \\
\text { ORGANIZAÇÃO }\end{array}$ & $100 \%$ Adequado & Sem prioridades \\
\hline $5^{\circ}$ & $\begin{array}{l}\text { CRITÉRIO } 2 \text { E = } \\
\text { DISPONIBILIDADE DE } \\
\text { CAPITAL }\end{array}$ & $100 \%$ Adequado & Sem prioridades \\
\hline
\end{tabular}

Fonte: Elaborada pelos autores

Com base nesse quadro, elaborou-se um plano resumido de gestão ambiental, o 5W2H, que visa apresentar soluções à empresa na melhoria da gestão ambiental do aspecto deficitário.

NIVEL DE TECNOLOGIA UTILIZADA (critério 2b)

- (What?) O quê?

$\mathrm{R}$ : A empresa precisa procurar utilizar uma quantidade maior de recursos renováveis

\section{- (Why?) Por quê?}

$\mathrm{R}$ : Conseguirá com isso uma maior preservação ambiental

\section{- (When?) Quando?}

R: Um prazo de dois anos é o suficiente para a empresa se adaptar

- (Where?) Onde?

R: Na sede da Vonpar Refrescos S.A., em Antônio Carlos

\section{-(Who?) Quem?}

R: Essa iniciativa deve vir da administração da empresa e deve ser executada por todos os funcionários da empresa

\section{- (How?) Como?}

R: Uma solução seria desenvolver uma nova fórmula para os refrigerantes que utilizem como ingredientes produtos renováveis.

- (How Much?) Quanto custa?

R: Valores não orçados

Acredita-se que, se a empresa adotar esse plano resumido de gestão ambiental, ela possua condições de melhorar a sustentabilidade do nível de tecnologia utilizada e, por consequência, melhorar a sustentabilidade global da empresa. 


\section{Considerações Finais}

Tendo a Contabilidade fundamental importância no processo de gestão ambiental, e por tal assunto estar se tornando mais evidente, tanto no meio acadêmico como no meio corporativo, este estudo teve como objetivo analisar o comportamento da sustentabilidade ambiental de uma indústria de bebidas, evidenciando seu processo produtivo, a fim de se verificar os impactos causados por esse processo, por meio das ferramentas de gestão ambiental com suporte da Contabilidade.

A problemática deste trabalho que estava resumida nas questões: (i) Qual a sustentabilidade ambiental global da indústria? (ii) Qual a sustentabilidade ambiental evidenciada no processo produtivo? foi devidamente dirimida, mostrando uma sustentabilidade global de $83,76 \%$, considerada adequada, e com sustentabilidade do processo produtivo de $76,47 \%$, adequada, mas com subcritério deficitário. Conseguiu-se com isso atingir os objetivos específicos.

A análise de sustentabilidade ambiental da empresa evidenciou que ela possui alguns pontos deficitários e regulares que precisam ser melhorados, a fim de se obter o máximo de desempenho ambiental, apesar de apresentar grandes números de aspectos adequados que conduzem à conclusão de que a empresa possui uma gestão ambiental no mínimo razoável, e que está trabalhando constantemente para melhorá-la.

Foi possível também observar a preocupação da empresa com a comunidade onde está inserida e com seus colaboradores, deixando nítido, dessa maneira, que a responsabilidade ambiental da empresa é também uma preocupação com os stakeholders.

Este estudo foi realizado em apenas uma empresa de bebidas, não sendo possível a comparabilidade da sustentabilidade ambiental no ramo. Além disso, este trabalho foi realizado em um único período de tempo, o que também não permitiu a comparabilidade e a evolução da sustentabilidade com o tempo, caracterizando, assim, esses dois fatos como limitação deste estudo.

Com base nas limitações apresentadas, sugere-se que, em futuros trabalhos, sejam realizadas análises em mais de uma empresa do mesmo ramo a fim de se obter comparabilidade do desempenho ambiental no setor, assim como se sugere repetir este estudo ao longo dos anos com o objetivo de avaliar a evolução da sustentabilidade ambiental com o passar do tempo.

\section{Referências}

ARAÚJO, A. P. L. et al. Gestão de Aspectos e Impactos Ambientais em um 
condomínio com envolvimento da Contabilidade Ambiental. In: CONGRESSO UFSC DE CONTROLADORIA E FINANÇAS E INICIAÇÃO CIENTÍFICA EM CONTABILIDADE, 1, 2007, Florianópolis. Anais. Florianópolis: Universidade Federal de Santa Catarina, 2007.

BALDISSERA, B. M. et al. Análise da sustentabilidade ambiental na empresa lavanderia ecológica. In: CONGRESSO UFSC DE CONTROLADORIA E FINANÇAS E INICIAÇÃO CIENTÍFICA EM CONTABILIDADE, 2, 2008, Florianópolis. Anais. Florianópolis: Universidade Federal de Santa Catarina, 2008.

CAMPANHOL, E. M.; SMITH, M. S. J.; PAULA, N. S. Ações Ambientais e a Evidenciação Contábil: um estudo nas empresas de curtimento de couro de Franca e região. In: CONGRESSO UFSC DE CONTROLADORIA E FINANÇAS E INICIAÇÃO CIENTÍFICA EM CONTABILIDADE, 1, 2007, Florianópolis. Anais. Florianópolis: Universidade Federal de Santa Catarina, 2007.

FERREIRA, L. F. et al. Contabilidade Ambiental Sistêmica. In: CONGRESSO UFSC DE CONTROLADORIA E FINANÇAS E INICIAÇÃO CIENTÍFICA EM CONTABILIDADE, 2, 2008, Florianópolis. Anais. Florianópolis: Universidade Federal de Santa Catarina, 2008.

FREITAS, C. L. et al. Análise de Sustentabilidade Ambiental: Um estudo de caso na Vonpar Refrescos S.A. In: CONGRESSO UFSC DE CONTROLADORIA E FINANÇAS E INICIAÇÃO CIENTÍFICA EM CONTABILIDADE, 2, 2008, Florianópolis. Anais. Florianópolis: Universidade Federal de Santa Catarina, 2008.

GIL, Antônio Carlos. Como elaborar Projetos de Pesquisa. 4. ed. São Paulo: Atlas, 2002.

KRAEMER, M. E. P. Contabilidade Ambiental: Relatório para um Futuro Sustentável, Responsável e Transparente.Disponível em : < http://www.universoambiental.com.br/Contabilidade/Contabilidade_FuturoSust.htm $>$. Acesso em: 16 nov. 2009.

KRAEMER, Maria Elisabete Pereira. A Contabilidade como instrumento de gestão ambiental. Disponível em: $<$ http://www.gestiopolis.com/ $>2002$. Acesso em: 17 nov. 2009.

LERÍPIO, A. A. GAIA. Um método de gerenciamento de aspectos e impactos ambientais. Florianópolis: UFSC, 2001. Tese (Doutorado em Engenharia de Produção). Universidade Federal de Santa Catarina, 2001. 
MACHADO FILHO, C. P. Responsabilidade Social e Governança: O Debate e as Implicações. São Paulo: Pioneira Thompson Learning, 2006.

PFITSCHER, E. D. Gestão e sustentabilidade através da Contabilidade e controladoria ambiental: estudo de caso na cadeia produtiva de arroz ecológico. Florianópolis, 2004, 252 p. Tese (Doutorado em Engenharia de Produção) - Programa de Pós-Graduação em Engenharia de Produção, Universidade Federal de Santa Catarina, 2004.

RICHARDSON, Roberto Jarry. Pesquisa Social: Métodos e Técnicas. 3. ed. São Paulo: Atlas, 1999.

TINOCO, J. E. P.; KRAEMER, M. E. P. Contabilidade e Gestão Ambiental. São Paulo: Atlas, 2004.

TINOCO, J. E. P.; ROBLES, L. T. Contribuição ao desenvolvimento da Contabilidade da gestão ambiental e da sua divulgação: estudo de casos de três empresas brasileiras com atuação global. In: REVISTA DO CENTRO DE CIÊNCIAS ADMINISTRATIVAS. Fortaleza, v. 12, n. 1 p. 115-129, ago. 2006.

VONPAR REFRESCOS S.A. Disponível em: < http://www.vonpar.com.br/site/ content/home/> Acesso em: 17 fev. 2009.

WIKIPÉDIA. Disponível em: < http://pt.wikipedia.org/wiki/Página_principal > Acesso em: 18 fev. 2009.

YIN, R. Estudo de Caso: planejamento e métodos. 3. ed. Porto Alegre: Bookman, 2005. 
